\title{
Expression levels of long non-coding RNA HOXA distal transcript antisense RNA and metabotropic glutamate receptor 1 in pancreatic carcinoma, and their prognostic values
}

\author{
XIAOQING WANG $^{1 *}$, LILI XIAO ${ }^{2 *}$ and HAITAO $\mathrm{YU}^{3}$ \\ ${ }^{1}$ Central Laboratory and ${ }^{2}$ Department of Digestive Diseases, Daqing Oilfield General Hospital, Daqing, Heilongjiang 163001; \\ ${ }^{3}$ Department of Nephrology, Daqing Longnan Hospital, Daqing, Heilongjiang 163453, P.R. China
}

Received August 23, 2017; Accepted February 1, 2018

DOI: $10.3892 / 01.2018 .8519$

\begin{abstract}
As a type of malignant tumor developed at the pancreas, the prognosis of pancreatic carcinoma is usually poor, and $>90 \%$ patients will sucumb to this disease $<5$ years after diagnosis. Therefore, early detection and treatment of this disease are important for improving the prognosis of patients. Long non-coding RNAs (IncRNAs) have been proven to serve pivotal functions in the development and progression of various tumors. The lncRNA HOXA distal transcript antisense RNA (HOTTIP), which serves an oncogenic role in different types of malignant tumors, has also been reported to be closely correlated with the migration and invasion of pancreatic carcinoma. In addition, the metabotropic glutamate receptor 1 (mGluR1) is also associated with the progression of various types of human cancer; however, its functionality in pancreatic carcinoma is largely unknown. In the present study, the expression levels of HOTTIP and mGluR1 were compared between pancreatic carcinoma and adjacent normal healthy tissues, and the correlation between these expression levels was analyzed. The prognostic value of HOTTIP and mGluR1 in pancreatic carcinoma was also examined. It was observed that the expression levels of HOTTIP and mGluR1 were upregulated in pancreatic carcinoma tissues and pancreatic carcinoma cells, while the expression of HOTTIP was able to positively affect the expression of mGluR 1 . In addition, high expression levels of HOTTIP were significantly correlated with the tumor size and distant metastasis. These data suggested that HOTTIP and mGluR1 may potentially serve as biomarkers for the prognosis of pancreatic carcinoma.
\end{abstract}

Correspondence to: Dr Haitao Yu, Department of Nephrology, Daqing Longnan Hospital, 35 Patriotic Way, Ranghulu, Daqing, Heilongjiang 163453, P.R. China

E-mail: rjfidq0701@163.com

*Contributed equally

Key words: pancreatic carcinoma, HOXA distal transcript antisense RNA, metabotropic glutamate receptor 1, prognostic value

\section{Introduction}

As one of the leading causes of cancer-associated mortality, pancreatic carcinoma affects $\sim 1 / 10,000$ people and results in $\sim 200,000$ mortalities each year worldwide (1). The prognosis of pancreatic carcinoma is usually poor, and the mortality rate of this disease in China within 5 years is $>90 \%$ (2). It has been demonstrated that the incidence of pancreatic carcinoma is closely associated with chronic pancreatitis, smoking, aging, male gender, obesity, diabetes mellitus and imbalanced diet among other factors (3). Although various treatment strategies have been developed to treat pancreatic carcinoma, surgical resection remains the most effective approach to treat this disease. However, surgical treatment following diagnosis is only suitable in $<20 \%$ of patients, and the overall 5 -year survival rate of patients with pancreatic carcinoma remains at $<5 \%$ (4). Therefore, early diagnosis and treatment are crucial for improving the survival of patients affected by pancreatic carcinoma.

Long non-coding RNAs (lncRNA) is a group of non-protein coding RNAs with a length of $>200$ nucleotides (5). Numerous studies have indicated that IncRNAs serve pivotal roles in the onset, development and progression of a variety of human diseases, including different types of cancer (6-8). The IncRNA HOXA distal transcript antisense RNA (HOTTIP) has been proven to be able to participate in the progression of pancreatic carcinoma through different pathways $(9,10)$. Although the direct involvement of metabotropic glutamate receptor 1 (mGluR1) in pancreatic carcinoma has not been reported thus far, the pivotal functions of glutamine in the growth of pancreatic carcinoma indicate the possible participation of mGluR1 in this disease (11). In an osteosarcoma study, Li et al (12) observed that the lncRNA HOTTIP, which is closely correlated with the poor prognosis of patients with osteosarcoma, may potentially serve as a prognostic marker of this disease. In view of these observations, it will be reasonable to hypothesize that the lncRNA HOTTIP and mGluR1 may also have prognostic values in pancreatic carcinoma.

In the present study, the expression levels of HOTTIP and mGluR1 in pancreatic carcinoma and adjacent normal healthy tissues were detected and compared, while the correlation between these expression levels was analyzed. The prognostic 
value of HOTTIP and mGluR1 in pancreatic carcinoma was also discussed.

\section{Materials and methods}

Patients. A total of 211 patients with pancreatic carcinoma admitted at the Daqing Longnan Hospital hospital (Daqing, China) between January 2008 and January 2013 were selected. All patients were diagnosed by histological evaluation according to the 'guidelines for the diagnosis and treatment of pancreatic cancer' established by the Chinese Medical Association, Branch of Pancreas Surgery (2014 edition). Among the 211 patients, 40 patients were subjected to surgery, whilst patients who were not appropriate for surgical operation were exluced from the study. The 40 patients received surgical operations included 19 males and 21 females, and their ages ranged between 21 and 78 years with a mean age of $44 \pm 8.1$ years. Distant metastasis was observed in 23 patients. A primary tumor diameter of $>2 \mathrm{~cm}$ was observed in 28 patients, while the primary tumor diameter was $<2 \mathrm{~cm}$ in 12 patients. Cancer tissues and adjacent normal tissue at $2 \mathrm{~cm}$ around the tumor were collected during the surgical procedures. The present study was approved by the Ethics Committee of the Daqing Longnan Hospital, and all patients signed informed consent. Patients were followed up for 8 months to monitor the survival conditions.

Cell lines and cell culture. The normal pancreatic cell line CRL-2279 ${ }^{\mathrm{TM}}$ and pancreatic cancer cell line CRL-2549 were purchased from the American Type Culture Collection (Manassas, VA, USA). CRL-2279 ${ }^{\text {тм }}$ cells were cultured with ATCC-formulated Dulbecco's modified Eagle's medium (cat. no. 30-2002) containing 5\% fetal bovine serum, while CRL-2549 ${ }^{\mathrm{TM}}$ cells were cultured with ATCC-formulated RPMI-1640 medium (cat. no. 30-2001) containing $10 \mathrm{U} / \mathrm{ml}$ human recombinant insulin and $15 \%$ fetal bovine serum. The two cell lines were cultured in an incubator at $37^{\circ} \mathrm{C}$ with $5 \%$ $\mathrm{CO}_{2}$. Cells were harvest during the logarithmic growth phase for subsequent experiments.

Establishment of HOTTIP overexpression and silencing cell lines. HOTTIP small interfering RNA (siRNA; cat. no. 4390771; Thermo Fisher Scientific, Inc.) and Silencer ${ }^{\mathrm{TM}}$ Select Negative Control No. 1 siRNA (cat. no. 4390843; Thermo Fisher Scientific, Inc.) were used for silencing of the HOTTIP expression in cells. Due to the commerical nature of these products, sequence information wasnot available. In addition, a HOTTIP overexpression vector was established by inserting an EcoRI-EcoRI fragment containing full length HOTTIP into pIRSE2-EGFP (Clontech Laboratories, Inc., Palo Alto, CA, USA). Prior to transfection, the pancreatic cancer CRL-2549 ${ }^{\mathrm{TM}}$ cells were cultured at $37^{\circ} \mathrm{C}$ overnight to reach 80-90\% confluent. Lipofectamine 2000 transfection reagent (cat. no. 11668-019; Invitrogen; Thermo Fisher Scientific, Inc.) was used for transfection with the siRNA or overexpression vector according to the manufacturer's protocol.

Reverse transcription-quantitative polymerase chain reaction (RT-qPCR). Cancer and adjacent normal tissues were ground in liquid nitrogen, and total RNA was extracted using TRIzol reagent (Invitrogen; Thermo Fisher Scientific, Inc., Waltham, MA, USA). Total RNA from in vitro cultured cells was also extracted using TRIzol reagent. The concentration and quality of the RNA samples were examined by a NanoDrop ${ }^{\mathrm{TM}} 2000$ spectrophotometer (Thermo Fisher Scientific, Inc.), and only the RNA samples with a ratio of A260/A280 between 1.8 and 2.0 were used. RT was then conducted with SuperScript III Reverse Transcriptase (Thermo Fisher Scientific, Inc.) to synthesize cDNA from total RNA. A qPCR reaction system was subsequently prepared using SYBR ${ }^{\circledR}$ Green Real-Time PCR Master Mix (Thermo Fisher Scientific, Inc.). The following primers were used in the qPCR reactions: HOTTIP, 5'-AAC GATGTGTGTGTGCCTTGAT-3' (forward) and 5'-TGGTCC GACAGGGTGAATT-3' (reverse); mGluR1, 5'-AGCGCCTCC AGTTGGCCT-3' (forward) and 5'-TGCGTGCAATACGAT TGGTT-3' (reverse); $\beta$-actin, 5'-GACCTCTATGCCAACACA GT-3' (forward) and 5'-AGTACTTGCGCTCAGGAGGA-3' (reverse). The CFX96 Touch $^{\mathrm{TM}}$ Real-Time PCR Detection System (Bio-Rad Laboratories, Inc., Hercules, CA, USA) was used to conduct the qPCR reactions under the following conditions: $95^{\circ} \mathrm{C}$ for $50 \mathrm{sec}$, followed by 40 cycles of $95^{\circ} \mathrm{C}$ for $12 \mathrm{sec}$ and $60^{\circ} \mathrm{C}$ for $35 \mathrm{sec} . \mathrm{Cq}$ values were processed using the $2^{-\Delta \Delta \mathrm{Cq}}$ method (13). The relative expression level of each gene was normalized to that of the endogenous control, $\beta$-actin.

Western blot analysis. Subsequent to total protein extraction using Radioimmunoprecipitation Assay Lysis and Extraction Buffer (Thermo Fisher Scientific, Inc.), the protein concentration was measured using a bicinchoninic acid protein assay kit (catalog number, 23225; Thermo Fisher Scientific, Inc.) Protein samples $(30 \mu \mathrm{g})$ were then subjected to $15 \%$ SDS-PAGE gel electrophoresis, followed by transfer to a polyvinylidene difluoride membrane. Following blocking with 5\% skimmed milk at room temperature for $1.5 \mathrm{~h}$, the membranes were washed with Tris-buffered saline/Tween 20 (TBST) and incubated with primary antibodies, including the rabbit anti-mGluR1 (1:2,000; ab82211; Abcam, Cambridge, MA, USA) and rabbit anti- $\beta$-actin $(1: 1,000$; ab8226; Abcam) antibodies, overnight at $4^{\circ} \mathrm{C}$. Membranes were then washed with TBST and incubated with anti-rabbit horseradish peroxidase-conjugated IgG secondary antibody (1:1,000; MBS435036; MyBioSource, Inc., San Diego, CA, USA) at room temperature for $1 \mathrm{~h}$. Subsequent to washing with TBST, an enhanced chemiluminescence detection reagent (Sigma-Aldrich; Merck KGaA, Darmstadt, Germany) was added to detect the signals, and signals were scanned using MyECL imager (Thermo Fisher Scientific). ImageJ software (version 1.8.0; National Institutes of Health, Bethesda, MD, USA) was then used to calculate the relative expression level of mGluR1 according to that of the endogenous control, $\beta$-actin.

Cell migration and invasion assay. A Transwell cell migration assay (BD Biosciences, San Jose, CA, USA) was performed in order to examine the migration of cells. Briefly, cells were transferred to the upper chamber of 6 -well plate at $5 \times 10^{4}$ cells per well, while ATCC-formulated RPMI-1640 medium containing 20\% fetal bovine serum (Sigma-Aldrich; Merck $\mathrm{KGaA}$ ) was used to fill the lower chamber. After $24 \mathrm{~h}$, membranes were collected and stained with $0.5 \%$ crystal violet (Sigma-Aldrich; Merck KGaA) for $25 \mathrm{~min}$. The number 
of stained cells was calculated under an optical microscope (Olympus Corp., Tokyo, Japan). An invasion assay was also performed using the same method, with the exception that the upper chamber was pre-coated with Matrigel (cat. no. 356234; EMD Millipore, Billerica, MA, USA).

Statistical analysis. SPSS version 19.0 software (IBM Corp., Armonk, NY, USA) was used for all statistical analyses. Data are expressed as the mean \pm standard deviation. Comparison of data between two groups was performed using Student's t-test. The Kaplan-Meier method was used to draw the survival curves, followed by comparison of survival curves using the log-rank test. The correlation between the expression levels of HOTTIP and mGluR1 was analyzed by Spearman analyses. $\mathrm{P}<0.05$ was considered to indicate a difference that was statistically significant.

\section{Results}

Expression of HOTTIP and mGluR1 in cancer and adjacent healthy tissues. The expression levels of HOTTIP and mGluR1 mRNA in cancer and adjacent healthy tissues of 40 patients with pancreatic carcinoma were detected by RT-qPCR. As shown in Fig. 1, the expression levels of HOTTIP and mGluR1 mRNA were significantly higher in cancer tissues as compared with those in adjacent healthy tissues, indicating the possible involvement of HOTTIP and mGluR1 in the development of pancreatic carcinoma. Furthermore, Spearman analyses demonstrated that the expression of HOTTIP mRNA in cancer tissues was positively correlated with the expression of mGluR1 ( $r=0.59789$; $\mathrm{P}<0.01$; data not shown).

Correlation of the expression levels of HOTTIP and mGluRI with the clinicopathological features and prognostic values. Using the median HOTTIP and mGluR1 mRNA expression levels in cancer tissues as the cutoff value, the 40 patients with pancreatic carcinoma were divided into the high $(n=20)$ and low $(n=20)$ HOTTIP expression groups, as well as the high $(n=20)$ and low $(n=20)$ mGluR1 expression groups. As shown in Table I, the mRNA expression levels of HOTTIP and mGluR1 were significantly positively correlated with the tumor size $(\mathrm{P}=0.01$ and $\mathrm{P}=0.02$, respectively $)$ and distant metastasis $(\mathrm{P}=0.01$ and $\mathrm{P}=0.000$, respectively), but were not correlated with the gender $(\mathrm{P}=0.73$ and $\mathrm{P}=0.94$, respectively) and age of patients $(\mathrm{P}=0.73$ and $\mathrm{P}=0.59$, respectively). Furthermore, survival curves were calculated using Kaplan-Meier plots to evaluate the prognostic value of HOTTIP and mGluR1 mRNA in pancreatic carcinoma, and these curves were compared by log-rank test. The result revealed that the overall survival of pancreatic carcinoma patients with a high expression level of HOTTIP or mGluR1 mRNA was significantly reduced in comparison with that of patients with a low expression level of HOTTIP or mGluR1 mRNA ( $\mathrm{P}=0.01$ and $\mathrm{P}=0.00$, respectively; Fig. 2 ).

Expression levels of HOTTIP and mGluR1 in normal pancreatic and pancreatic cancer cell lines. The expression levels of HOTTIP and mGluR1 in the normal pancreatic cell line CRL-2279 ${ }^{\mathrm{TM}}$ and the pancreatic cancer cell line
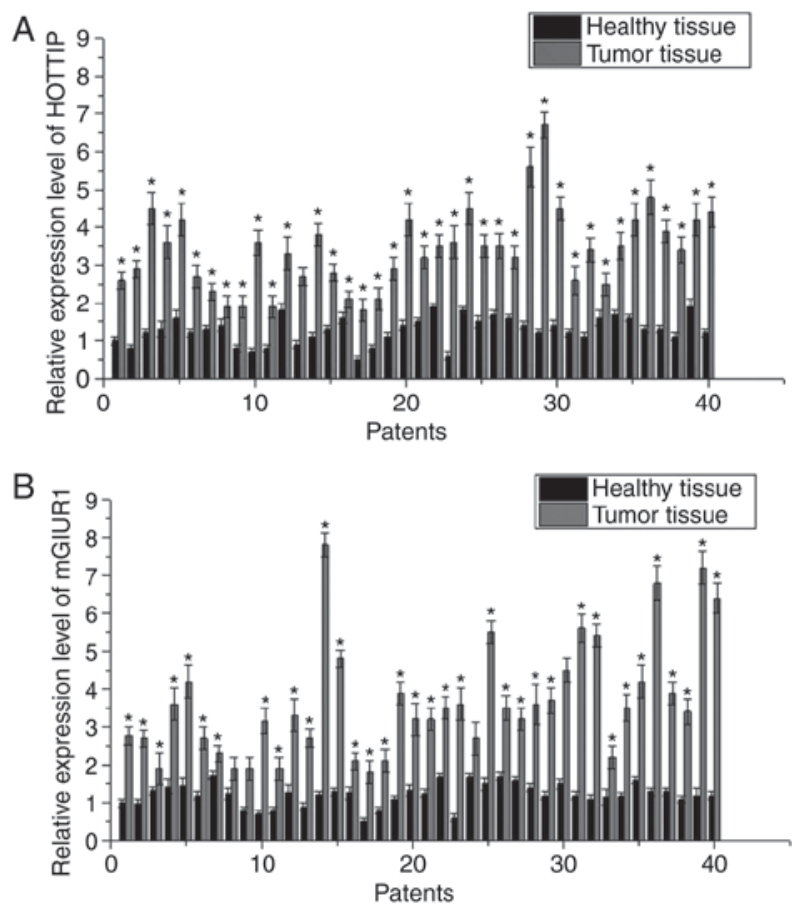

Figure 1. mRNA expression levels of (A) HOTTIP and (B) mGluR1 in cancer tissue and adjacent healthy tissues were determined by reverse transcription-quantitative polymerase chain reaction. ${ }^{*} \mathrm{P}<0.05$ vs. adjacent healthy tissues. HOTTIP, HOXA distal transcript antisense RNA; mGluR1, metabotropic glutamate receptor 1 .

CRL-2549 ${ }^{\mathrm{TM}}$ were detected by RT-qPCR and western blot analysis. As shown in Fig. 3A, the expression of HOTTIP was significantly increased in the CRL-2549 ${ }^{\mathrm{TM}}$ cell line as compared with that in CRL-2279 ${ }^{\mathrm{TM}}$ cells $(\mathrm{P}=0.02)$. In addition, compared with the normal pancreatic CRL-2279 ${ }^{\mathrm{TM}}$ cell line, the expression of mGluR1 was significantly increased in the pancreatic cancer CRL-2549 ${ }^{\mathrm{TM}}$ cell line at the mRNA and protein levels $(\mathrm{P}<0.05$; Fig. 3B-D).

Effect of HOTTIP knockdown and overexpression on the expression of $m$ GluR1. CRL-2549 ${ }^{\mathrm{TM}}$ cell lines with HOTTIP siRNA silencing or overexpression were constructed to investigate the effects of HOTTIP on the expression of mGluR1. As shown in Fig. 4A, the expression of HOTTIP was significantly decreased in siRNA-treated cells and significantly increased in the HOTTIP overexpression cells $(\mathrm{P}<0.05)$. However, no significant differences were identified between the control cell line and the siRNA negative control or overexpression negative control cells. These observations indicated that the HOTTIP knockdown and overexpression CRL-2549 ${ }^{\mathrm{TM}}$ cells were successfully established. As shown in Fig. 4B, compared with the control cell line, the expression of mGluR1 mRNA was significantly reduced in HOTTIP knockdown cells and significantly increased in HOTTIP overexpression cells $(\mathrm{P}<0.05)$. In addition, as shown in Fig. 4C and D, the expression of mGluR1 protein was also significantly reduced in HOTTIP knockdown cells and significantly increased in HOTTIP overexpression cells $(\mathrm{P}<0.05)$. These results suggested that the expression of mGluR1 was positively regulated by HOTTIP at the mRNA and protein levels. 
Table I. Correlation of the expression levels of HOTTIP and mGluR1 with the clinicopathological features of patients.

\begin{tabular}{|c|c|c|c|c|c|c|c|c|}
\hline \multirow[b]{2}{*}{ Feature } & \multirow[b]{2}{*}{ Groups } & \multirow[b]{2}{*}{ Total, $\mathrm{n}$} & \multicolumn{2}{|c|}{ HOTTIP expression } & \multirow[b]{2}{*}{ P-value } & \multicolumn{2}{|c|}{$\begin{array}{c}\text { mGluR1 } \\
\text { expression }\end{array}$} & \multirow[b]{2}{*}{ P-value } \\
\hline & & & High, $n$ & Low, $\mathrm{n}$ & & High & Low & \\
\hline \multirow[t]{2}{*}{ Gender } & Male & 19 & 9 & 10 & \multirow[t]{2}{*}{0.78276} & 11 & 8 & \multirow[t]{2}{*}{0.937030} \\
\hline & Female & 21 & 12 & 9 & & 13 & 8 & \\
\hline \multirow[t]{2}{*}{ Age (years) } & $>35$ & 27 & 12 & 15 & \multirow[t]{2}{*}{0.73144} & 10 & 17 & \multirow[t]{2}{*}{0.593478} \\
\hline & $\leq 35$ & 13 & 5 & 8 & & 6 & 7 & \\
\hline \multirow[t]{2}{*}{ Tumor size $(\mathrm{cm})$} & $>2$ & 28 & 22 & 6 & \multirow[t]{2}{*}{$<0.01$} & 19 & 9 & \multirow[t]{2}{*}{0.024032} \\
\hline & $\leq 2$ & 12 & 3 & 9 & & 4 & 8 & \\
\hline \multirow[t]{2}{*}{ Distant metastasis } & Yes & 23 & 19 & 4 & \multirow[t]{2}{*}{$<0.01$} & 17 & 6 & \multirow[t]{2}{*}{0.004277} \\
\hline & No & 17 & 4 & 13 & & 5 & 12 & \\
\hline
\end{tabular}

HOTTIP, HOXA distal transcript antisense RNA; mGluR1, metabotropic glutamate receptor 1.
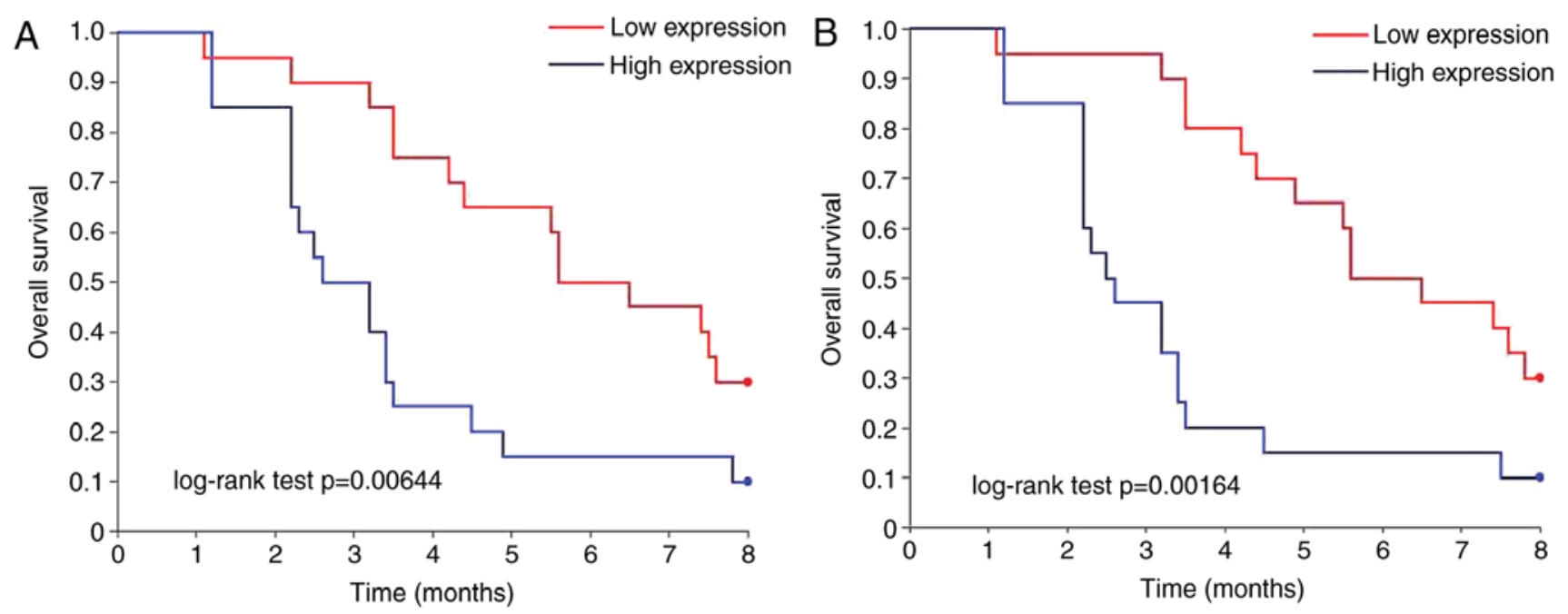

Figure 2. Overall survival demonstrated by Kaplan-Meier plots according to the mRNA level of (A) HOTTIP and (B) mGluR1. HOTTIP, HOXA distal transcript antisense RNA; mGluR1, metabotropic glutamate receptor 1 .

Effect of HOTTIP knockdown and overexpression on pancreatic cancer cell migration and invasion. As shown in Fig. 5A, the migration ability of HOTTIP knockdown pancreatic cancer CRL-2549 ${ }^{\mathrm{TM}}$ cells was significantly lower in comparison with that of control CRL-2549 ${ }^{\mathrm{TM}}$ cells $(\mathrm{P}<0.05)$. In addition, the migration ability of the HOTTIP overexpression pancreatic cancer CRL-2549 ${ }^{\mathrm{TM}}$ cells was significantly higher compared with that of control CRL-2549 ${ }^{\mathrm{TM}}$ cells $(\mathrm{P}<0.05)$. However, no significant differences in migration ability were detected between the control and two negative control groups. Similar results were observed for the invasion ability of cells. A significantly lower invasion ability was identified in the HOTTIP knockdown CRL-2549 ${ }^{\mathrm{TM}}$ cells, while a significantly higher invasion ability was observed in the HOTTIP overexpression CRL-2549 ${ }^{\mathrm{TM}}$ cells, as compared with the control cell line $(\mathrm{P}<0.05)$. These data suggested that HOTTIP expression was positively correlated with the migration and invasion abilities of pancreatic cancer cells.

\section{Discussion}

Despite the advances in understanding the underlying mechanism and improving the diagnosis and treatment of pancreatic carcinoma, this disease remains one of the malignant tumors with the highest mortality, severely affecting patient survival (4). The lncRNA HOTTIP has been proven to be involved in the progression of various types of human cancer. In a gastric cancer study, Ye et al (14) reported that the expression of the IncRNA HOTTIP was positively correlated with the invasion ability of tumor cells, while increased expression of HOTTIP contributed to the poor prognosis of patients. Furthermore, the expression level of HOTTIP was frequently upregulated in hepatocellular carcinoma tissues (15), and increased expression of this IncRNA was observed to be closely associated with the progression of hepatocellular carcinoma and the treatment outcomes of patients affected by this disease (16). A recent study reported that HOTTIP was also able to promote the proliferation, migration and survival of pancreatic carcinoma 

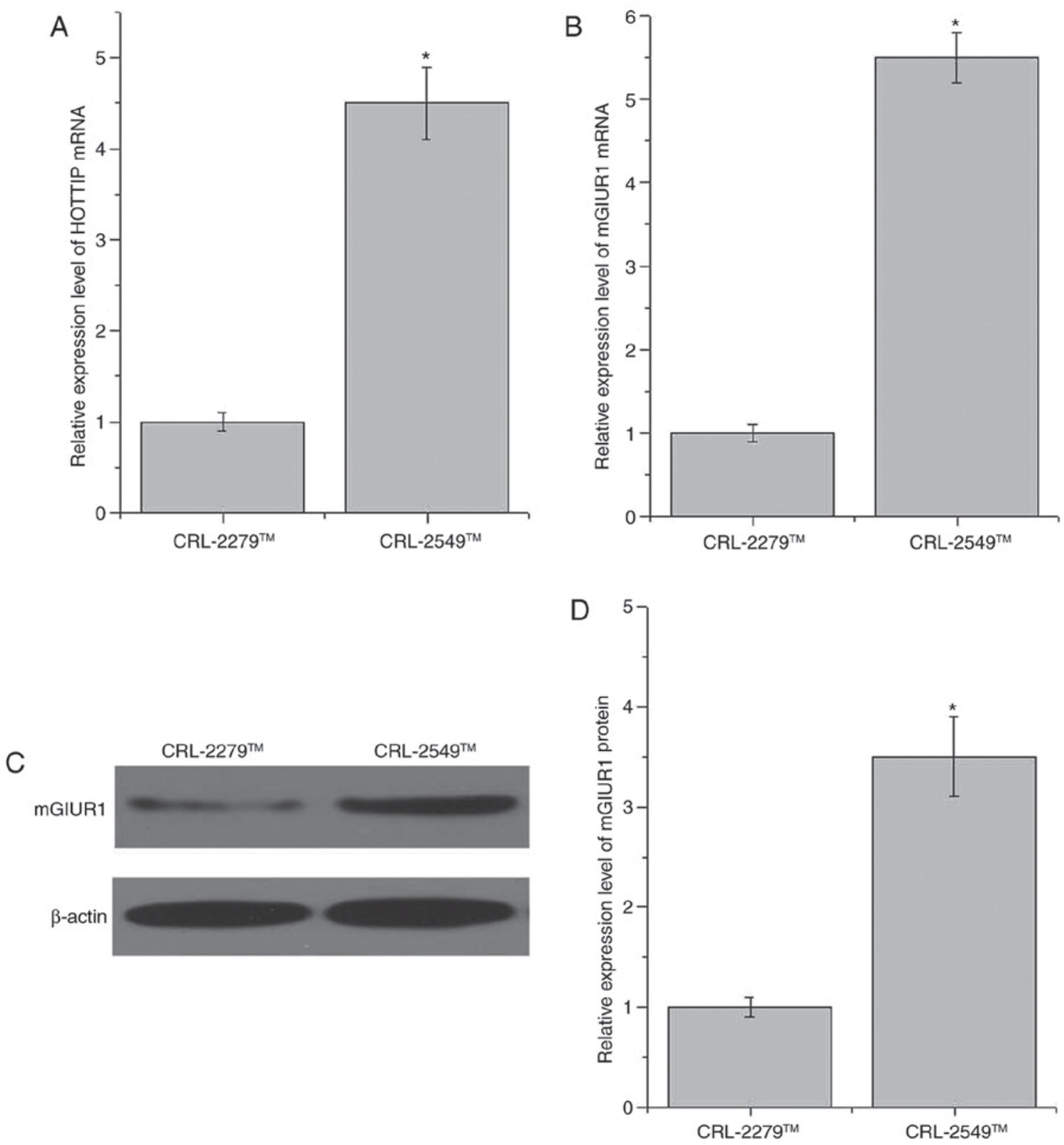

Figure 3. Relative mRNA expression levels of (A) HOTTIP and (B) mGluR1 in the normal pancreatic and pancreatic cancer cell lines. (C) Representative results of western blot analysis. (D) Relative expression level of mGluR1 protein in normal pancreatic and pancreatic cancer cell lines. ${ }^{*} \mathrm{P}<0.05$ vs. normal pancreatic cell line. HOTTIP, HOXA distal transcript antisense RNA; mGluR1, metabotropic glutamate receptor 1.

cells (10). Consistent with this previous study, the expression level of HOTTIP was reported to be significantly increased in pancreatic carcinoma tissues as compared with adjacent healthy tissues in the present study. In addition, HOTTIP was proven to be positively correlated with the migration and invasion ability of in vitro cultured pancreatic carcinoma cells. Therefore, the current study further confirmed the involvement of HOTTIP in pancreatic carcinoma.

The expression of mGluRs is mainly detected in the central nervous system, with these receptors mediating neurotransmitter release and neuronal excitability (17). Subtypes of mGluRs are typically selectively expressed in tissues of different cancer types, indicating the involvement of mGluRs in tumorigenesis (18). As a member of the mGluR family, the functionality of mGluR1 has been well studied in breast cancer. During the development of breast cancer, mGluR1 has been demonstrated to promote angiogenesis, which in turn contributes to the progression of the tumor (19). Another study conducted by Speyer et al (20) reported that mGluR1 may serve as a potential target for the treatment of patients with breast cancer. As a receptor of glutamate, the functionality of mGluR in the development of pancreatic carcinoma remains known. However, the functions of glutamine in the growth of pancreatic carcinoma indicate the involvement of mGluR1 in this disease (11). In the present study, the expression level of mGluR1 was observed to be significantly higher in pancreatic carcinoma tissues and in vitro cultured pancreatic carcinoma cells as compared with that in the corresponding normal controls, indicating the participation of mGluR1 in this disease.

The present study also demonstrated that the expression level of mGluR1 was positively correlated with the expression level of the IncRNA HOTTIP. In addition, HOTTIP 

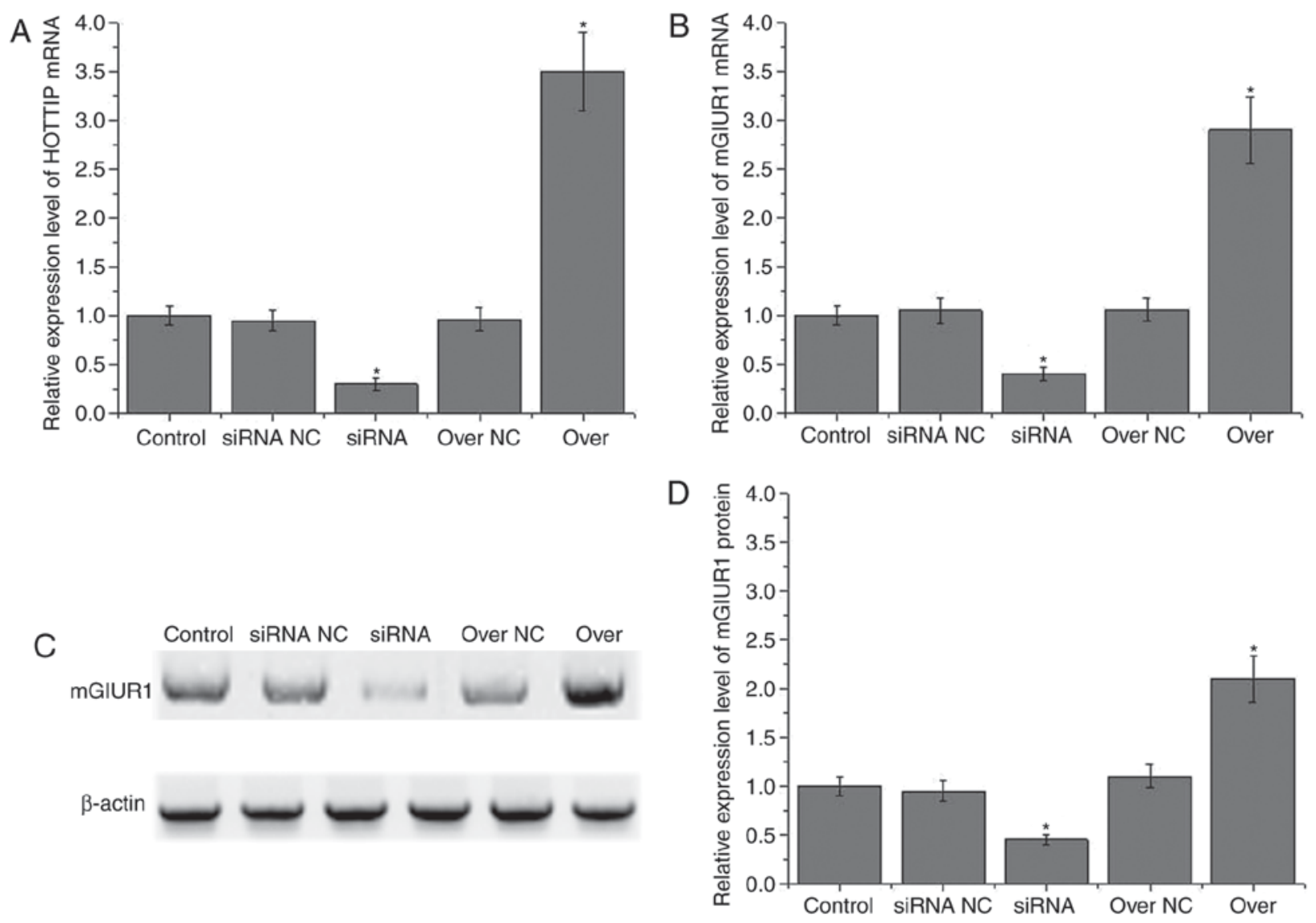

Figure 4. Effect of HOTTIP knockdown and overexpression of the expression of mGluR1. Relative mRNA expression levels of (A) HOTTIP and (B) mGluR1 in different cell lines. (C) Representative results of western blot analysis. (D) Relative expression levels of mGluR1 protein in different cell lines. " $\mathrm{P}<0.05 \mathrm{vs.}$ control cell line. NC negative control; over, overexpression. HOTTIP, HOXA distal transcript antisense RNA; mGluR1, metabotropic glutamate receptor 1; siRNA, small interfering RNA; NC, negative control; Over, overexpression.
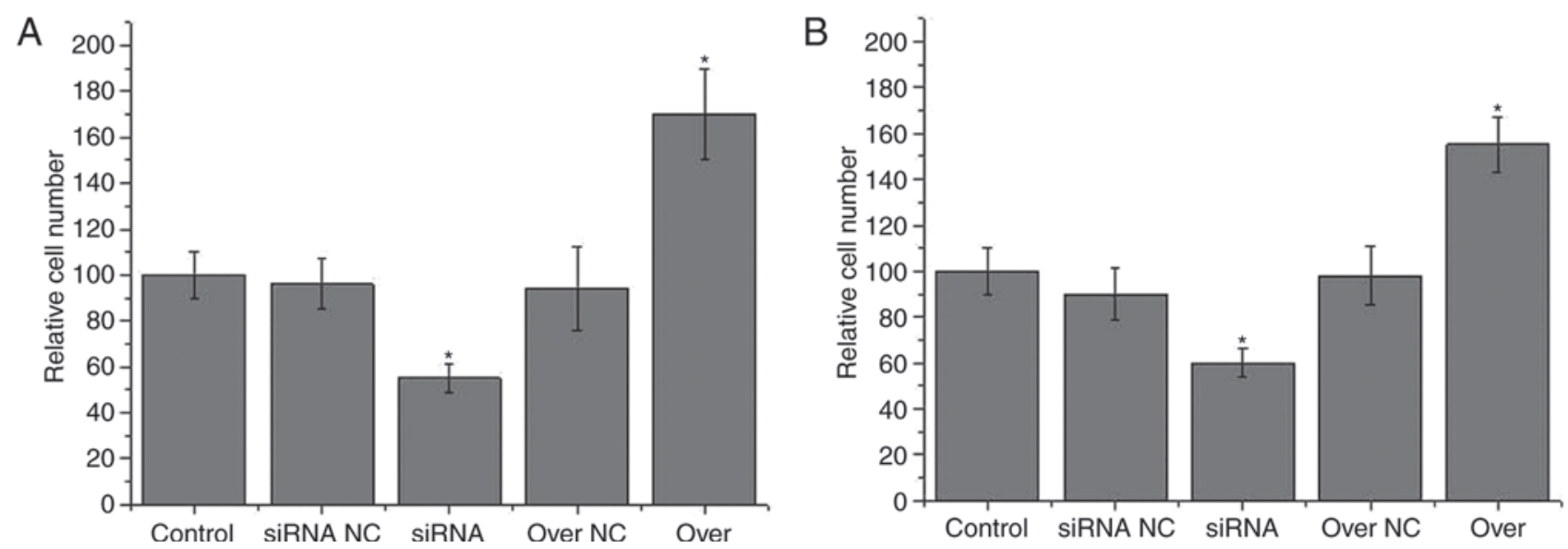

Figure 5. Effect of HOTTIP knockdown and overexpression on pancreatic cancer cell migration and invasion. (A) Relative migration abilities and (B) relative invasion abilities of cells in different cell lines. "P<0.05 vs. control. HOTTIP, HOXA distal transcript antisense RNA; siRNA, small interfering RNA; NC, negative control; Over, overexpression.

knockdown was able to downregulate the expression of mGluR1, whereas the expression of mGluR1 was significantly upregulated by HOTTIP overexpression. To the best of our knowledge, no studies on the regulation of mGluR expression by IncRNA HOTTIP have been reported. However, glutamine metabolism, which is important for the development of various types of tumors, such as bladder cancer, has been proven to be regulated by lncRNAs (21), indicating the possible interactions between lncRNAs and mGluRs. Furthermore, the results of the present study revealed that increased expression level of HOTTIP and mGluR1 were significantly correlated with the tumor size and distant metastasis, indicating that HOTTIP and mGluR1 may potentially serve as prognostic markers for pancreatic carcinoma. 
In conclusion, the expression levels of HOTTIP and mGluR1 were significantly higher in pancreatic carcinoma tissues and cells as compared with the corresponding controls, while HOTTIP was able to positively regulate the expression of mGluR1. In addition, increased expression levels of HOTTIP and mGluR 1 were significantly correlated with the tumor size and distant metastasis. These data suggested that HOTTIP and mGluR1 may potentially serve as prognostic markers in pancreatic carcinoma patients.

\section{Acknowledgements}

Not applicable.

\section{Funding}

No funding was received.

\section{Availability of data and materials}

All data generated or analyzed during this study are included in this published article.

\section{Authors' contributions}

XW, LX and HY designed experiments, XW and LX performed experiments, $\mathrm{HY}$ analyzed data and wrote the manuscript. All authors read the manuscript.

\section{Ethics approval and consent to participate}

This study was approved by the Ethics Committee of the Daqing Longnan Hospital. All participants provided written informed consent.

\section{Consent for publication}

All participants provided written informed consent for the publication of their data.

\section{Competing interests}

The authors declare that they have no competing interests.

\section{References}

1. Chen W, Zheng R, Baade PD, Zhang S, Zeng H, Bray F, Jemal A, Yu XQ and He J: Cancer statistics in China, 2015. CA Cancer J Clin 66: 115-132, 2016.

2. Chen W, Zheng R, Zuo T, Zeng H, Zhang S and He J: National cancer incidence and mortality in China, 2012. Chin J Cancer Res 28: 1-11, 2016.
3. Vincent A, Herman J, Schulick R, Hruban RH and Goggins M: Pancreatic cancer. Lancet 378: 607-620, 2011.

4. Sharma C, Eltawil KM, Renfrew PD, Walsh MJ and Molinari M: Advances in diagnosis, treatment and palliation of pancreatic carcinoma: 1990-2010. World J Gastroenterol 17: 867-897, 2011.

5. Perkel JM: Visiting 'noncodarnia'. Biotechniques 54: 301, 303-304, 2013.

6. Wang K, Liu F, Zhou LY, Long B, Yuan SM, Wang Y, Liu CY, Sun T, Zhang XJ and Li PF: The long noncoding RNA CHRF regulates cardiac hypertrophy by targeting miR-489. Circ Res 114: 1377-1388, 2014.

7. Takahashi K, Yan I, Haga H and Patel T: Long noncoding RNA in liver diseases. Hepatology 60: 744-753, 2014.

8. Prensner JR and Chinnaiyan AM: The emergence of lncRNAs in cancer biology. Cancer Discov 1: 391-407, 2011.

9. Li Z, Zhao X, Zhou Y, Liu Y, Zhou Q, Ye H, Wang Y, Zeng J, Song Y, Gao W, et al: The long non-coding RNA HOTTIP promotes progression and gemcitabine resistance by regulating HOXA13 in pancreatic cancer. J Transl Med 13: 84, 2015.

10. Cheng Y, Jutooru I, Chadalapaka G, Corton JC and Safe S: The long non-coding RNA HOTTIP enhances pancreatic cancer cell proliferation, survival and migration. Oncotarget 6: 10840-10852, 2015.

11. Son J, Lyssiotis CA, Ying H, Wang X, Hua S, Ligorio M, Perera RM, Ferrone CR, Mullarky E, Shyh-Chang N, et al: Glutamine supports pancreatic cancer growth through a KRAS-regulated metabolic pathway. Nature 496: 101-105, 2013.

12. Li F, Cao L, Hang D, Wang F and Wang Q: Long non-coding RNA HOTTIP is up-regulated and associated with poor prognosis in patients with osteosarcoma. Int J Clin Exp Pathol 8: 11414-11420, 2015.

13. Livak KJ and Schmittgen TD: Analysis of relative gene expression data using real-time quantitative PCR and the 2(-Delta Delta C(T)) method. Methods 25: 402-408, 2001.

14. Ye H, Liu K and Qian K: Overexpression of long noncoding RNA HOTTIP promotes tumor invasion and predicts poor prognosis in gastric cancer. Onco Targets Ther 9: 2081-2088, 2016.

15. Tsang FHC, Au SLK, Wei L, Fan DN, Lee JM, Wong CC, Ng IO and Wong CM: Long non-coding RNA HOTTIP is frequently up-regulated in hepatocellular carcinoma and is targeted by tumour suppressive miR-125b. Liver Int 35: 1597-1606, 2015.

16. Quagliata L, Matter MS, Piscuoglio S, Arabi L, Ruiz C, Procino A, Kovac M, Moretti F, Makowska Z, Boldanova T, et al: Long noncoding RNA HOTTIP/HOXA13 expression is associated with disease progression and predicts outcome in hepatocellular carcinoma patients. Hepatology 59: 911-923, 2014.

17. Zhang H, Cilz NI, Yang C, Hu B, Dong H and Lei S: Depression of neuronal excitability and epileptic activities by group II metabotropic glutamate receptors in the medial entorhinal cortex. Hippocampus 25: 1299-1313, 2015.

18. Yu LJ, Wall BA, Wangari-Talbot J and Chen S: Metabotropic glutamate receptors in cancer. Neuropharmacology 115: 193-202, 2017.

19. Speyer CL, Hachem AH, Assi AA, Johnson JS, DeVries JA and Gorski DH: Metabotropic glutamate receptor-1 as a novel target for the antiangiogenic treatment of breast cancer. PLoS One 9: e88830, 2014.

20. Speyer CL, Smith JS, Banda M, DeVries JA, Mekani T and Gorski DH: Metabotropic glutamate receptor-1: A potential therapeutic target for the treatment of breast cancer. Breast Cancer Res Treat 132: 565-573, 2012.

21. Li H J, Li X, Pang H, Pan JJ, Xie XJ and Chen W: Long non-coding RNA UCA1 promotes glutamine metabolism by targeting miR-16 in human bladder cancer. Jpn J Clin Oncol 45: 1055-1063, 2015. 